\title{
ВмJ Global Health Delivering maternal and neonatal health interventions in conflict settings: a systematic review
}

Mariella Munyuzangabo, ${ }^{1}$ Michelle F Gaffey, ${ }^{1}$ Dina S Khalifa, ${ }^{1}$ Daina Als, ${ }^{1}$ Anushka Ataullahjan, ${ }^{1}$ Mahdis Kamali, ${ }^{1}$ Reena P Jain (D) , ${ }^{1}$ Sarah Meteke, ${ }^{1}$ Amruta Radhakrishnan, ${ }^{1}$ Shailja Shah (D , ${ }^{1}$ Fahad J Siddiqui, ${ }^{1,2}$ Zulfiqar A Bhutta ${ }^{1,3}$

To cite: Munyuzangabo M, Gaffey MF, Khalifa DS, et al. Delivering maternal and neonatal health interventions in conflict settings: a systematic review. BMJ Global Health 2021;5:e003750. doi:10.1136/ bmjgh-2020-003750

Handling editor Seye Abimbola

- Additional material is published online only. To view please visit the journal online (http://dx.doi.org/10.1136/ bmjgh-2020-003750).

Received 18 August 2020 Revised 15 January 2021 Accepted 26 January 2021
Check for updates

(C) Author(s) (or their employer(s)) 2021. Re-use permitted under CC BY. Published by BMJ.

${ }^{1}$ Centre for Global Child Health, The Hospital for Sick Children, Toronto, Ontario, Canada ${ }^{2}$ Health Services and Systems Research, Duke-NUS Graduate Medical School, Singapore ${ }^{3}$ Centre of Excellence in Women and Child Health, Aga Khan University, Karachi, Pakistan

Correspondence to Dr Zulfiqar A Bhutta; zulfiqar.bhutta@sickkids.ca

\section{ABSTRACT}

Background While much progress was made throughout the Millennium Development Goals era in reducing maternal and neonatal mortality, both remain unacceptably high, especially in areas affected by humanitarian crises. While valuable guidance on interventions to improve maternal and neonatal health in both non-crisis and crisis settings exists, guidance on how best to deliver these interventions in crisis settings, and especially in conflict settings, is still limited. This systematic review aimed to synthesise the available literature on the delivery on maternal and neonatal health interventions in conflict settings.

Methods We searched MEDLINE, Embase, CINAHL and PsycINF0 databases using terms related to conflict, women and children, and maternal and neonatal health. We searched websites of 10 humanitarian organisations for relevant grey literature. Publications reporting on conflict-affected populations in low-income and middleincome countries and describing a maternal or neonatal health intervention delivered during or within 5 years after the end of a conflict were included. Information on population, intervention, and delivery characteristics were extracted and narratively synthesised. Quantitative data on intervention coverage and effectiveness were tabulated but no meta-analysis was undertaken.

Results 115 publications met our eligibility criteria. Intervention delivery was most frequently reported in the sub-Saharan Africa region, and most publications focused on displaced populations based in camps. Reported maternal interventions targeted antenatal, obstetric and postnatal care; neonatal interventions focused mostly on essential newborn care. Most interventions were delivered in hospitals and clinics, by doctors and nurses, and were mostly delivered through non-governmental organisations or the existing healthcare system. Delivery barriers included insecurity, lack of resources and lack of skilled health staff. Multi-stakeholder collaboration, the introduction of new technology or systems innovations, and staff training were delivery facilitators. Reporting of intervention coverage or effectiveness data was limited. Discussion The relevant existing literature focuses mostly on maternal health especially around the antenatal period. There is still limited literature on postnatal care in conflict settings and even less on newborn care. In crisis settings, as much as in non-crisis settings, there is a need to focus

\section{Key questions}

What is already known?

- The insecurity, population displacement and health service disruption that are associated with armed conflict may increase both maternal and neonatal mortality.

- While there is guidance available on the essential interventions for mothers and newborns in humanitarian crises, there is still a lack of guidance on how best to deliver these interventions, especially in conflict settings where there are even more barriers to the access of services.

What are the new findings?

- Maternal health interventions were mostly delivered by skilled health workers including doctors and nurses and in hospitals and clinics; the majority of reported interventions focused on antenatal care and its different components.

- Although few, the reported newborn interventions focused on essential newborn care such as neonatal resuscitation and kangaroo mother care, and were also mostly delivered by skilled health workers in clinics and hospitals.

- Among the reported barriers to intervention delivery were the lack of safety, population displacement, and the lack of resources and skilled health workers; however, facilitators included the availability of funding, multisectoral collaboration and the availability of training for staff.

- There is still a wide gap in reporting on newborn health, with very few eligible publications reporting on interventions targeting newborns.

on the first day of birth for both maternal and neonatal health. There is also a need to do more research on how best to involve community members in the delivery of maternal and neonatal health interventions.

PROSPERO registration number CRD42019125221.

\section{INTRODUCTION}

Maternal and newborn mortality remain two of the biggest challenges in global health. 


\section{Key questions}

What do the new findings imply?

- There is a need to do more evaluations on the use of lower-cadre health workers and community-based sites in the delivery of maternal health interventions.

- It is also important to assess the feasibility and importance of deploying people from the affected communities, especially in out-ofcamp settings where there may not be as many services/resources available.

- There is an urgent need to prioritise newborn health interventions. More research is needed on how best to deliver newborn interventions using lower-skilled health workers and at the community level.

Although much progress was made throughout the Millennium Development Goals era, about 810 women still die from pregnancy-related or childbirth-related complications every day. This is especially true in low/ middle-income countries (LMICs) where $94 \%$ of these deaths occur. ${ }^{1}$ Approximately 7000 newborns also die every day, ${ }^{2}$ accounting for $47 \%$ of all under- 5 child deaths, and with $36 \%$ of them occurring during the first 24 hours after birth and $73 \%$ within the first week. ${ }^{3}$ Although it has been shown that increasing coverage of antenatal care (ANC), skilled birth attendance and postnatal care for both the mother and the baby can prevent high maternal and neonatal mortality rates, ${ }^{4}$ data from existing surveys still show that many women and newborns are not reached with these essential interventions. ${ }^{1}$

Within humanitarian settings and especially in the context of armed conflict, insecurity coupled with displacement and service disruption produce an instability that may lead to a higher risk of maternal mortality. ${ }^{5}$ While increased maternal mortality may be a direct effect of armed conflict, it has also been shown that maternal mortality may remain elevated even $1-3$ years postconflict, indicating the longer terms effects of conflict on the disruption of essential health services for pregnant women. ${ }^{5}$ Newborn mortality has also been shown to increase in the context of armed conflict, ${ }^{6}$ and is highest in fragile settings and in countries that have recently experienced a humanitarian crisis. ${ }^{7}$

Comprehensive global guidance exists for addressing maternal and neonatal health (MNH) in non-crisis settings, including the interventions and services outlined in the Every Newborn Action Plan launched in $2014 .{ }^{8}$ Guidance is also available to support $\mathrm{MNH}$ in humanitarian crises, including the latest version of the Inter-Agency Field Manual on Reproductive Health in Humanitarian Settings and the Newborn Health in Humanitarian Settings-Field Guide, both released in 2018. ${ }^{9}{ }^{10}$ However, guidance on how best to deliver recommended interventions for pregnant women and newborns in humanitarian settings, and especially in conflict settings, is still very limited. A review on public health interventions that was included in the 2017 Lancet Series on Health in Humanitarian Crises highlighted the need for higher quality studies on $\mathrm{MNH}$ that focus on the most effective means of delivering those interventions in crisis contexts. ${ }^{11} 12$

The present review aimed to systematically synthesise the available indexed and grey literature reporting on the delivery of maternal and newborn interventions in conflict settings. We sought to characterise how and by whom such interventions have been and are being delivered to conflict-affected women and newborns and, if possible, to what extent and with what effectiveness.

\section{METHODS \\ Literature search}

Asystematic search of published literature from 1st January 1990 to 31st March 2018 was conducted; records were retrieved in MEDLINE, Embase, CINAHL and PsycINFO using OVID and EBSCO interfaces. We used sets of terms related to three concepts: (a) conflict; (b) women and children; and (c) MNH. Conflict-related terms included war, crisis, refugees and internally displaced persons (IDPs). Population-related terms included: women, children, pregnant, adolescents and newborn. $\mathrm{MNH}-$ related terms included: pregnancy, obstetrics, labour complications and neonatal care, among others. The full MEDLINE search syntax is provided in the online supplemental appendix A. Relevant publications from key systematic reviews ${ }^{11} 13-15$ were also hand searched for potentially relevant publications.

We searched the websites of 10 major humanitarian agencies and organisations that are actively involved in responding to or researchin conflict situations for grey literature on the implementation of health interventions in pregnant and postpartum women or newborns. These websites included: Emergency Nutrition Network, International Committee of the Red Cross, International Rescue Committee, Médecins Sans Frontières, Save the Children, United Nations (UN) Population Fund, UN High Commissioner for Refugees, UNICEF, Women's Refugee Commission and World Vision. We used broad terms for conflict and health interventions tailored to the search functionality of each website. Documents published from 1 January 2013 to 30 November 2018 were reviewed.

\section{Eligibility criteria}

Our eligibility criteria included publications reporting on populations affected by conflict in LMICs, as classified by the World Bank. ${ }^{16}$ Eligible publications must have described an MNH intervention targeting or including pregnant or postpartum women or neonates, and delivered during or within 5 years of cessation of a conflict. Where needed, we consulted online encyclopaedic sources as well as the UN Office for the Coordination of Humanitarian Affairs website for information on the duration of a specific conflict, to assess whether the time period of intervention delivery reported in a candidate publication was eligible. In order to identify the most 
informative resources from the large volume of grey literature available, the same inclusion criteria set for indexed literature was applied, with the additional requirement of explicit reporting on the delivery site and personnel for each intervention.

Non-English publications; case reports of a single patient; or publications reporting on military personnel, refugee populations in high-income countries, surgical techniques, or economic or mathematical modelling studies were excluded from our review. We also excluded systematic and other literature reviews, editorials, commentaries, first-person narratives, newspaper and magazine articles, opinion pieces, guidelines and studies where no specific health intervention was described (eg, prevalence studies).

\section{Data extraction and analysis}

All identified indexed records were downloaded into EndNote software ${ }^{17}$ and duplicates were removed. Unique records were subsequently added into Covidence software for screening. ${ }^{18}$ Two reviewers independently screened titles and abstracts for relevance, and any discrepancies were resolved through discussion or by a third reviewer, if necessary. A single reviewer then screened the full texts of potentially relevant publications to determine their eligibility for inclusion in this review. The same approach was applied to the grey literature, with two reviewers screening titles of retrieved publications for relevance and one reviewer assessing the full text to determine eligibility.

We used a customised form on the REDCap platform ${ }^{19}$ to extract relevant quantitative and qualitative information from all included publications. Data and information on key variables including setting, population characteristics, study design, intervention details and delivery characteristics including reported delivery barriers and facilitators, as well as quantitative data on coverage and effectiveness (when available), were extracted. Two reviewers entered the data in duplicate independently and any inconsistencies identified were resolved through a discussion or by a third reviewer.

Descriptive statistics were performed to summarise key characteristics of the intervention, including displacement status of the target population, delivery characteristics, and reported factors impeding or facilitating delivery. We plotted intervention delivery frequencies stratified by population displacement status, and we mapped reported interventions against reported delivery personnel and site, stratified by intervention type. We tabulated coverage and effectiveness estimates that were reported for pregnant or postpartum women or newborns, but metaanalysis was not conducted due to extensive variability in interventions, outcomes, study settings and populations. All descriptive analyses were conducted using Stata V.14.0 statistical software. ${ }^{20}$ Finally, we narratively synthesised reported information on delivery barriers and facilitators by classifying related information into subgroups and then into broader themes.

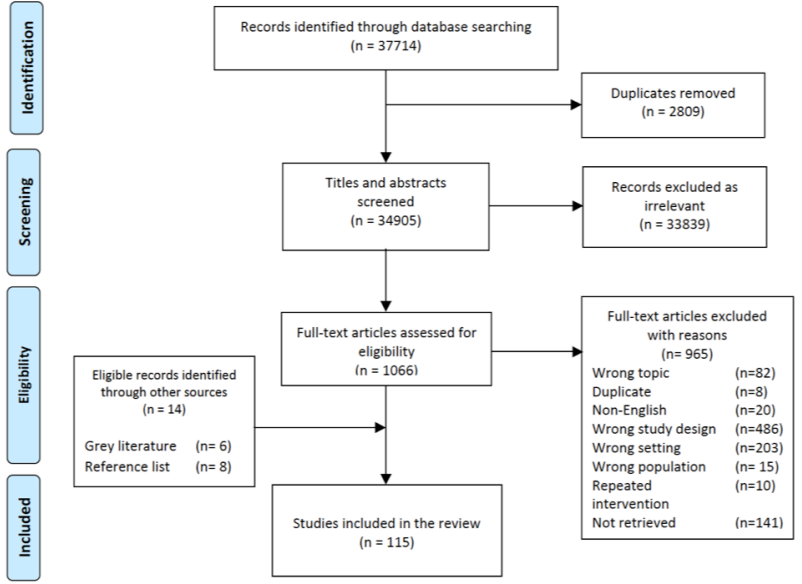

Figure 1 Preferred Reporting Items for Systematic Reviews and Meta-Analyses flow diagram: publication selection process for systematic review on the delivery of maternal and neonatal health interventions in conflict settings.

\section{Patient and public involvement}

Patients and/or the public were not involved in the design, or conduct, or reporting or dissemination plans of this systematic review of the literature.

\section{RESULTS}

\section{Characteristics of the included literature}

From 37714 indexed publications retrieved through our database search, 101 met our eligibility criteria. An additional 14 eligible publications were identified from our grey literature search, and from the reference lists of other reviews. A total of 115 publications were therefore included in this review (figure 1). ${ }^{21-135}$ Of these, only 26 reported on neonatal interventions. ${ }^{24} 262829333842445560$ $63717597106110-113116118120123124133135$

of all included publications are presented in the online supplemental appendix B.

Of the 115 included publications, $\mathrm{MNH}$ intervention delivery was most frequently reported in the sub-Saharan Africa region (43\%), followed by the East Asia and Pacific region (27\%), mainly in Thailand (figure 2 ). There were

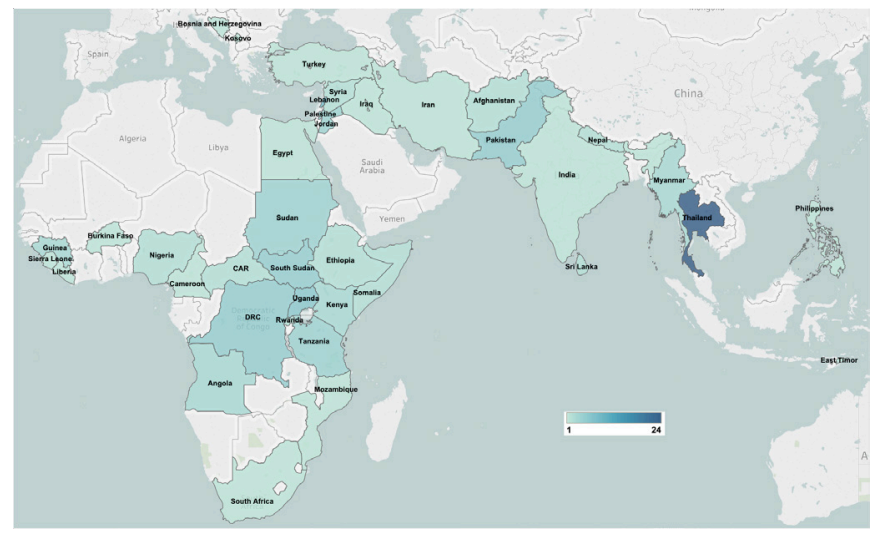

Figure 2 Geographical distribution of included publications. 
Table 1 Characteristics of included publications and included interventions

\section{Study and population characteristics $(\mathrm{N}=115)$}

\begin{tabular}{|c|c|}
\hline Geographical region* & $\mathbf{n}$ \\
\hline East Asia and Pacific & 31 \\
\hline Europe and Central Asia & 3 \\
\hline Latin America and the Caribbean & 0 \\
\hline Middle East and North Africa & 22 \\
\hline South Asia & 14 \\
\hline Sub-Saharan Africa & 50 \\
\hline Publication type & $\mathbf{n}$ \\
\hline Non-research report & 19 \\
\hline Mixed methods & 11 \\
\hline Observational study & 78 \\
\hline Qualitative study & 4 \\
\hline Quasi-experimental study & 0 \\
\hline Randomised controlled trial & 3 \\
\hline Displacement status of beneficiary population* & $\mathbf{n}$ \\
\hline Refugees & 75 \\
\hline IDPs & 36 \\
\hline Non-displaced & 20 \\
\hline Returning refugees & 2 \\
\hline Host & 11 \\
\hline Unreported & 12 \\
\hline Setting of displaced populations ${ }^{*} \dagger$ & $\mathbf{n}$ \\
\hline Camp & 52 \\
\hline Dispersed & 16 \\
\hline Mixed & 14 \\
\hline Unreported & 33 \\
\hline \multicolumn{2}{|l|}{ Intervention delivery characteristics $(\mathrm{N}=313)$} \\
\hline Target population type* & $\mathbf{n}$ \\
\hline Neonates ( $<28$ days) & 32 \\
\hline Pregnant women & 253 \\
\hline Postpartum women & 51 \\
\hline Implementation platform & $\mathbf{n}$ \\
\hline Existing health system & 148 \\
\hline NGO/UN agencies & 234 \\
\hline Military based & 3 \\
\hline Research based & 38 \\
\hline
\end{tabular}

${ }^{*}$ Publications and interventions can be included in more than one category.

†Only reflects publications that reported on displaced populations (refugees, IDPs or returning refugees).

IDPs, internally displaced persons; NGO, non-governmental organisations; UN, United Nations.

no studies reporting on interventions delivered within the Latin America and Caribbean region. The majority of included publications reported on observational studies $(68 \%)$, and $17 \%$ were non-research reports (table 1$)$.

More than half of the included publications reported on interventions delivered to refugees $(62 \%)$, and about one-third of those delivered to IDPs (27\%). There were

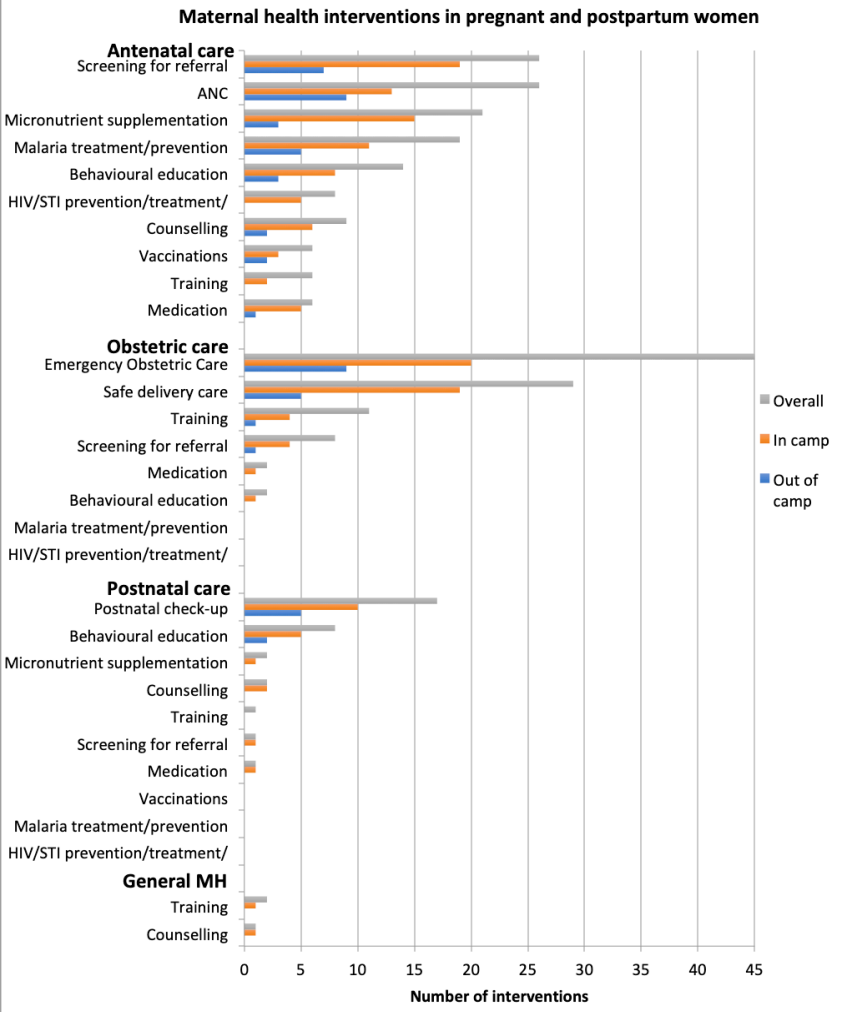

Figure 3 Maternal health interventions in pregnant and postpartum women. ANC, antenatal care; $\mathrm{MH}$, maternal health; STI, sexually transmitted infection.

also a few publications reporting on interventions delivered to non-displaced but conflict-affected populations and to host communities in countries with refugees. Among those publications reporting population displacement settings, intervention delivery to refugees and IDPs was reported most frequently in camp settings (45\%). Pregnant women were the most frequently reported intervention target populations, and most reported interventions were delivered by non-governmental organisations (NGOs) (including community-based organisations) or UN agencies, either through the existing healthcare system or in parallel.

\section{Maternal health interventions}

The reported interventions targeting pregnant or postpartum women covered different components of maternal health such as antenatal, obstetric and postnatal care, as well as general maternal health (figure 3). Within ANC, the most commonly reported interventions were screening interventions for HIV, sexually transmitted infections (STIs), malaria and anaemia; micronutrient supplementation; malaria prevention and treatment; and behavioural education activities. Of the publications that reported on the delivery of ANC, about $35 \%$ of them did not specify the components provided. Reported obstetric care interventions were mostly safe delivery care interventions and the provision of basic and comprehensive emergency obstetric care (EmOC), including caesarean sections. Other obstetric care interventions included 


\begin{tabular}{|c|c|c|c|c|c|c|c|c|c|}
\hline Imterenentors & $08 / 6 m$ & Doctors & Mures & Heath workers & 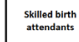 & 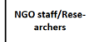 & cows & Teachers & treAs \\
\hline 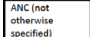 & A & A & A & A & A & A & & & A \\
\hline 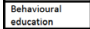 & $p$ & $A_{1} \quad \mathrm{P}$ & $A \quad P$ & $a_{A}$ & A $O$ O & $a_{A}$ & $A \circ p$ & & $A O P$ \\
\hline 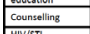 & & & \begin{tabular}{|lll}
$n$ & 6 \\
\end{tabular} & \begin{tabular}{|lll}
$A$ & $D_{6}$ \\
\end{tabular} & & $\begin{array}{ll}A & B \\
\end{array}$ & \begin{tabular}{|l|l} 
\\
\end{tabular} & & \\
\hline 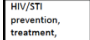 & A & A & A & A & A & & & & |A \\
\hline 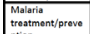 & & A & $a_{A}$ & A & A & $a_{A}$ & A & & |a \\
\hline \begin{tabular}{|l} 
tion \\
Metication
\end{tabular} & & $A 0$ & A & A & AO O & $O P$ & $A$ & & \\
\hline 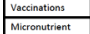 & & 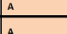 & A & A & a & & & & \\
\hline 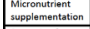 & & A & 4 a & A & 4 & $\begin{array}{ll}A & \text { P } \\
\end{array}$ & & & \\
\hline 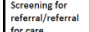 & $A 0$ & AO & a & A。 & A O & $A \quad P$ & A o & & \\
\hline $\begin{array}{l}\text { Sotatedefiver } \\
\text { card }\end{array}$ & 。 & 。 & $\circ$ & $\circ$ & o & 0 & o & & $\circ$ \\
\hline 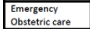 & $\circ$ & $\circ$ & $\circ$ & $\circ$ & $\circ$ & $\circ$ & & & $\circ$ \\
\hline 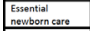 & & & & N & & N & & & \\
\hline & $\stackrel{\circ}{\circ}$ & $\circ$ & $\circ$ & 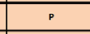 & $\circ$ & $\circ$ & $\circ$ & & . \\
\hline & A 0 & $\begin{array}{lll}A & 0 & \\
\end{array}$ & ite & A 0 P & 0 & 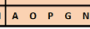 & & & \\
\hline
\end{tabular}

Figure 4 Reported maternal and neonatal health interventions by delivery personnel and intervention type. ANC, antenatal care; CHWs, community health workers; NGO, non-governmental organisation; STI, sexually transmitted infection; TBAs, traditional birth attendants.

training of healthcare workers and referral for care. Reported postnatal care interventions included postnatal check-ups within 48 hours of delivery, education activities and micronutrient supplementation among others. Reported general maternal health interventions mainly included training healthcare workers and counselling interventions.

When comparing mothers living in camps with those living outside of camps, more interventions were reported to be delivered to mothers based in camps (figure 3). Some interventions were not reported at all for women living outside of camps, such as training of health workers or interventions targeting the prevention of HIV and STIs during ANC. There were also very few postnatal care interventions and no general maternal health interventions reported to be delivered to out-ofcamp mothers.

\section{Delivery characteristics of maternal health interventions Personnel}

Trained health professionals were commonly reported personnel for maternal health interventions. These included doctors, nurses, health workers, skilled birth attendants (SBAs) and $\mathrm{OB} / \mathrm{GYN}$ specialists (figure 4). NGO staff and researchers were also reported to have delivered most maternal health interventions such as ANC, behavioural education, postnatal care and training. Community health workers (CHWs) were reported to deliver ANC interventions such as malaria treatment and prevention, micronutrient supplementation, behavioural education and counselling among others. Traditional birth attendants (TBAs) were not only involved in delivery care, but were also able to deliver some ANC interventions such as malaria prevention, medication and postnatal check-ups. There were no interventions delivered by community members such as civic leaders or trained civilians and there was only one training intervention where teachers were involved, which was a literacy programme for women.
When we compare in-camp and out-of-camp populations, in-camp mothers were reported to have access to a wider range of personnel compared with out-of-camp populations (data not shown). In-camp interventions were delivered by health workers, nurses, doctors and OB/GYN specialists, while for out-of-camp populations, health workers were the most reported delivery personnel, but with fewer specified professionals reported such as OB/GYN specialists, doctors and nurses. There was also only one reported instance of a TBA being used in an out-of-camp population and very few interventions were reported to be delivered by SBAs or NGO staff. There were few differences in delivery personnel between refugees and IDPs (data not shown), except that while CHWs are mainly used for behavioural education and referral in refugee populations, they were also used for the ANC interventions such as micronutrient supplementation or malaria prevention in IDP populations.

\section{Sites}

Maternal health interventions were mostly delivered using the inpatient and outpatient platforms, with most interventions reported to be delivered within either hospitals or clinics (figure 5). Other common delivery sites included health posts and mobile clinics, mostly for the delivery of ANC interventions. Community-based sites such as homes and communal spaces were also used for ANC and postnatal care interventions. There were few differences between in-camp and out-of-camp populations in terms of delivery sites (data not shown). There were no $\mathrm{MNH}$ interventions reported to be delivered in a hospital within out-of-camp populations, and there was also more use of communal spaces for delivery reported within these populations. Interventions targeted towards refugees were delivered more often in clinics and hospitals, with no reports of delivery using outreach sites such as health posts and mobile clinics and very few reporting delivery at the household (data not shown). Interventions targeted towards IDPs used outreach approaches more frequently, with interventions delivered at health posts and through mobile clinics.

\section{Newborn health interventions}

Very few studies reported on newborn care, and only about $10 \%$ of all interventions reported were targeting newborns. These interventions were focused mostly on essential newborn care such as neonatal resuscitation, kangaroo mother care and infection prevention. Other common interventions were postnatal check-ups, training of health workers and HIV prevention or follow-up through prevention of mother-to-child transmission (figure 6).

There were more reported interventions on newborns living in camps $(69 \%)$ compared with those living out of camps $(16 \%)$. The three most common newborn interventions in camps were essential newborn care, postnatal check-ups and training, while the most common intervention outside of camps was health worker training (figure 6). There were no reported instances of interventions targeting 


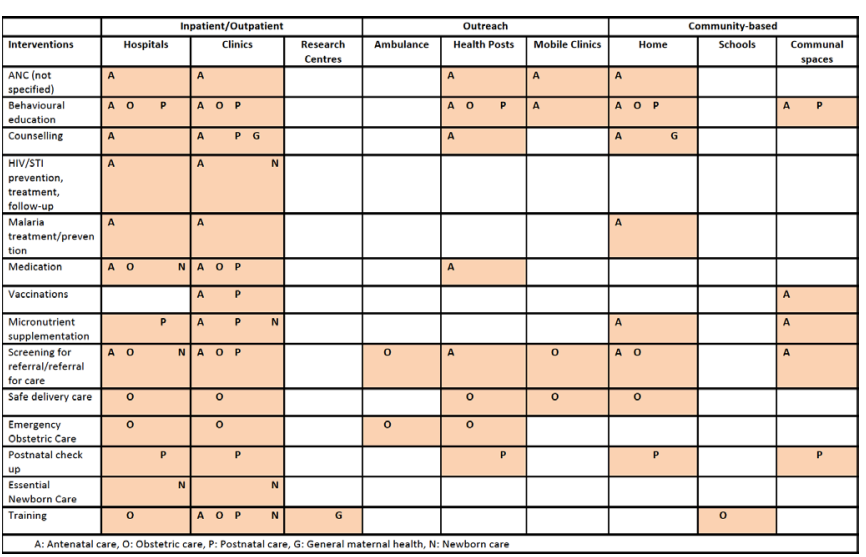

Figure 5 Reported maternal and neonatal health interventions by delivery site and intervention type. ANC, antenatal care; STI, sexually transmitted infection.

HIV or malaria or delivering vaccinations or micronutrient supplementation among newborns outside of camps.

\section{Delivery characteristics of newborn health interventions Personnel}

Newborn interventions were delivered by SBAs, doctors, nurses, health workers and NGO staff (figure 4). NGO staff were reported to deliver essential newborn care and training interventions. Trained TBAs were also reported to deliver essential newborn care. There were no reports of interventions delivered by CHWs or trained community members. There were no major differences between delivery personnel used for refugee compared with IDP populations. However, there were no reports of OB/GYN specialists being used to deliver newborn interventions among IDP populations. There were also no reports of nurses delivering newborn interventions in refugee populations. There were very few observations of interventions delivery among non-displaced newborns.

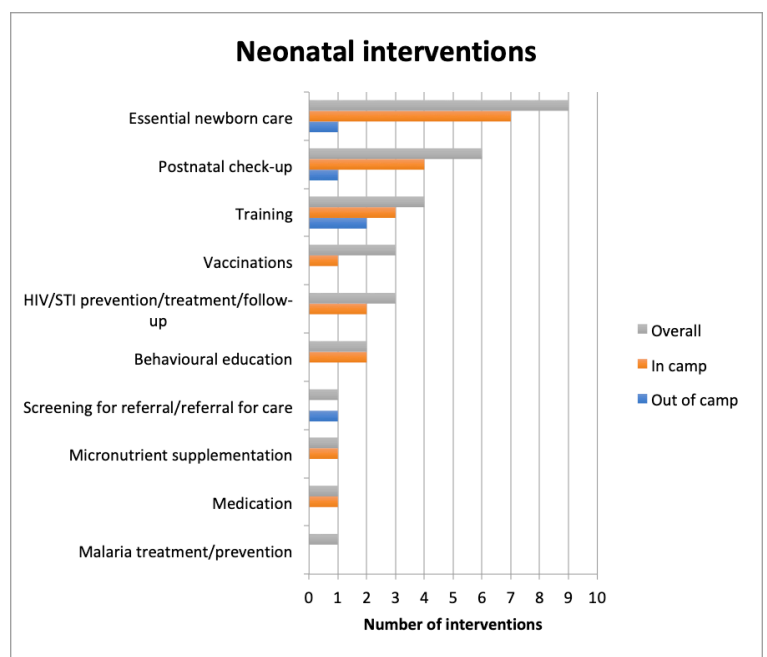

Figure 6 Neonatal health interventions. STI, sexually transmitted infection.
Sites

All newborn interventions were delivered in hospitals and clinics (figure 5) There were no reported newborn interventions delivered from an outreach or communitybased platform. With very limited reporting on newborn interventions delivered outside of camps, it is not possible to compare delivery sites by camp status.

\section{Reported coverage and effectiveness of MNH interventions}

Full details of the retrieved intervention coverage and effectiveness data are presented in the online supplemental appendices $\mathrm{C}$ and D. Most estimates were derived from camp-based refugee populations. The majority of reported outcomes in pregnant women assessed coverage of ANC interventions such as the proportion of women accessing four or more ANC visits or the proportion of women receiving different components of ANC such as behavioural education, HIV/STI testing or malaria treatment. Other commonly reported coverage outcomes were on obstetric care such as the rate of caesarean sections and other major obstetric interventions. There were very few outcomes on postnatal care, with only two publications reporting on the proportions of postpartum women attending a postnatal consultation.

The majority of maternal intervention effectiveness estimates reported on the odds of receiving all ANC medical tests or visits, or of delivering at home in women who had received a maternal and child health handbook or maternal education compared with those who had not. There were also a small number of estimates reported regarding the effect of having a CHW in a village on the likelihood of a pregnant women receiving ANC or of having SBA at birth.

The included publications reported very few coverage or effectiveness estimates for newborn interventions. Coverage estimates included those for initiation of breast feeding, kangaroo mother care, antiretroviral (ARV) prophylaxis and healthcare worker training. Effectiveness estimates reported on the rate of exclusive breast feeding after an educational intervention and the rate of death in infants in a special care baby unit after training health workers.

No meta-analysis of intervention coverage or effectiveness data was undertaken given the wide variation in outcome definitions and measures, population characteristics and study designs.

\section{Barriers to and facilitators of intervention delivery}

There were multiple reported barriers to delivering $\mathrm{MNH}$ interventions in conflict settings; key barriers and examples are presented in table 2 . The most commonly reported barriers were security constraints and displacement. Populations are often not able to access healthcare facilities due to security issues, and in some cases, because facilities have been destroyed. Continuous population movement also limits women's access to services, and as health workers are likely also affected by the conflict, there may be staff shortages and high turnover. 
Table 2 Reported barriers and facilitators in the implementation of MNH interventions

\section{Barriers}

Security

Being in an insecure environment was often mentioned as a hindrance to the delivery of interventions. Health facilities are destroyed, patients were also unable to access clinics due to security issues. This was especially relevant for services such as emergency obstetric care when women may need to be referred to hospitals.

Lack of resources Shortages of supplies/resources (medicine, diagnostic tests) during a period of conflict were also noted as barriers and hampered both maternal and newborn care. Materials such as gloves for delivery, obstetric equipment or beds for premature babies were some of the ones noted as missing. ${ }^{43} 111$

Population movement

The continuous population movement limits both delivery and access to health services.

Lack of skilled health workers The limited training of health workers was a major barrier in the delivery of interventions such as obstetric and newborn care. A few studies mentioned the lack of obstetric specialists as a barrier. ${ }^{43104}$ A short training although helping to increase knowledge was also noted as not being enough.

$\begin{array}{ll}\text { Social norms/stigma } & \text { This was noted as a barrier for both patients as well as healthcare workers. Refugees may } \\ & \text { also be stigmatised by their hosts. }{ }^{63} \\ \text { Lack of funding } & \text { Limited funding was also noted as a barrier as it limited to range of services and materials } \\ & \text { available. }\end{array}$

Limited movement for the women/cost barriers Conflict reduces means of generating income, especially during displacement. Therefore, the cost of getting health services or of transport might be weighed against other priorities. In some instances where healthcare is not subsidised, cost of care also influenced where women delivered. ${ }^{49}$

Staff affected by conflict Health services were also limited as staff are also affected by displacement and security concerns. Shortage of staff was a big concern and in some areas was caused by the warring party. In one study, the Taliban were preventing female health providers from working. ${ }^{106}$ Some areas also experienced a high staff turnover, especially in a prolonged conflict. ${ }^{134}$

$\begin{array}{ll}\text { Limited services } & \begin{array}{l}\text { Conflict reduces the range of available services. For maternal health, this was especially } \\ \text { dangerous in cases where there is limited EmOC services as needed surgical facilities were } \\ \text { not available or there was no training in the management of postpartum complications, }{ }^{3364} \\ \text { emergency referral services were also not always available. }\end{array} \\ \text { Quality of care } & \begin{array}{l}\text { There were some differences noted between the quality of care delivered at hospitals, } \\ \text { compared with clinics; hospitals having a higher quality. }{ }^{111} \text { ANC and postnatal care were also } \\ \text { not always delivered to their full extent. }\end{array} \\ \text { Lack of guidelines } & \begin{array}{l}\text { A few studies mentioned lack of guidelines for STI prevention or lack of newborn-specific } \\ \text { clinical and referral protocols as barriers to implementation. }\end{array}\end{array}$

\section{Facilitators}

Collaboration Multisectoral collaboration between international NGOs, the Ministry of Health and existing district health offices/public sector was noted as facilitators. Working with local NGOs was also a facilitator as they are already connected to the community.

Staff training

Training improved the skills of health workers and increased motivation. Continuous supervision/refresher training was encouraged, especially if provided by trained paediatricians or obstetricians. ${ }^{122}$ S-CORT modules are an innovative approach that focuses on training on the clinical services included in the MISP. ${ }^{122}$ One NGO developed a simple and low-cost 38hour training course to upgrade the skills of TBAs. ${ }^{113}$

\begin{tabular}{|c|c|}
\hline $\begin{array}{l}\text { Availability of funding/ } \\
\text { resources }\end{array}$ & Having adequate funding allowed for more resources. \\
\hline $\begin{array}{l}\mathrm{CHW} \text { involvement/outreach } \\
\text { workers }\end{array}$ & $\begin{array}{l}\text { Having maternal CHWs from the same community or refugee population was noted as a } \\
\text { facilitator in educating women about maternal health. }\end{array}$ \\
\hline Use of existing infrastructure & Using the existing infrastructure facilitated the delivery of interventions. ${ }^{71} 110$ \\
\hline $\begin{array}{l}\text { Technological/systems } \\
\text { innovations }\end{array}$ & $\begin{array}{l}\text { Improving systems such as introducing an ultrasound in outreach settings was noted as a } \\
\text { facilitator, }{ }^{23} \text { or introducing ANC into family medicine clinics as shown by Homan et al. }{ }^{57} \text { Using } \\
\text { GIS technology with a mobile clinic was shown as being effective in delivering SRH services } \\
\text { to IDPs. }{ }^{114} \text { Having a free ambulance along with good infrastructure (roads, telephone network) } \\
\text { was a facilitator. }{ }^{91}\end{array}$ \\
\hline
\end{tabular}


Table 2 Continued

\section{Barriers}

Refugee participation

Refugee participation was noted as a facilitator as it provided manpower and community leadership. ${ }^{90}$ Refugee services run by refugees were shown to be feasible if there is sustained funding and technical assistance. ${ }^{130}$

Dedicated staff

Having dedicated healthcare workers was noted multiple times as being a facilitator. ${ }^{86} 106121$

ANC, antenatal care; CHWs, community health workers; EmOC, emergency obstetric care; GIS, geographic information system; IDPs, internally displaced persons; MISP, Minimum Initial Service Package; MNH, maternal and neonatal health; NGOs, non-governmental organisations; $\mathrm{SRH}$, sexual and reproductive health; STI, sexually transmitted infection; TBAs, traditional birth attendants.

Other reported barriers include lack of infrastructure and resources to provide EmOC services, lack of specialised health workers and stigma towards refugees. A few publications also mentioned a lack of guidelines, such as newborn-specific protocols.

Despite the barriers, there were other factors that were reported to facilitate the delivery of interventions. The presence of skilled and dedicated staff, as well as having a trained doctor/midwife present to provide mentorship for other staff, were noted as facilitators. Another important facilitator reported was the further training of existing healthcare workers. Involving CHWs and training TBAs from the same populations as those being served were also noted as facilitators; these are usually trusted members of the community with whom local women may feel more comfortable. Other reported facilitators include multisectoral collaboration between NGOs and the existing health system, having adequate funding, and refugee participation, among others (table 2).

\section{DISCUSSION \\ Principal findings}

The majority of reported maternal health interventions delivered in conflict settings focused on ANC and its different components. Caesarean sections and the availability of EmOC more broadly were also reported relatively commonly, but with little detail on EmOC components. Postnatal care was reported relatively infrequently, also with little detail about what such care was composed of. Maternal health interventions were reported to be delivered mainly by skilled health workers and within hospitals and clinics, but health posts and mobile clinics were also cited, as well as homes and communal spaces at the community level. We did note some differences in delivery personnel and sites between in-camp and outof-camp mothers, where out-of-camp mothers are mostly attended to by lower cadres of health workers and where communal spaces are used more often.

There were very few reported newborn health interventions, focusing mostly on essential newborn care delivered by trained health workers, or in some cases, by TBAs. Nearly all reported newborn interventions were delivered within hospitals or clinics, with only one (postnatal check-up) delivered in a health post, and none were delivered using a community-based approach. Due to the limited literature, it is difficult to compare the delivery of interventions for neonates born in camps with those born outside of camps.

Conflict hinders the delivery of $\mathrm{MNH}$ interventions and common barriers reported include the lack of safety, population displacement, limited resources and services, and a lack of skilled health workforce. Where the workforce is available, there are other barriers such as lack of clear guidelines. However, other factors such as availability of funding, multisectoral collaboration, training and supervision of staff, as well as involving CHWs and refugees, were all reported to have facilitated the delivery of MNH interventions.

Most publications that included quantitative data reported on intervention coverage, and the majority on ANC coverage specifically. There were very few publications that reported on effectiveness of $\mathrm{MNH}$ interventions; some studies did compare the rates of caesarean sections or other major obstetric interventions before and after the introduction of an intervention such as the training of health workers. Reported quantitative data on newborn health were mainly coverage estimates of the initiation of ARV prophylaxis in infants exposed to HIV and on initiation of breast feeding. It was not possible to infer differences in intervention coverage or effectiveness by delivery characteristics because of the large variability in outcome measures and populations.

\section{Evidence gaps}

No publications reported on the use of lay community members in the delivery of MNH interventions in conflict settings. It has already been shown that involving community members, including men and community leaders, in the promotion and delivery of maternal health interventions such education/campaigns can be highly effective, ${ }^{136}$ and refugee participation was also noted as a facilitator in one of the studies.

We found very limited literature on newborn care, perhaps reflecting the relative neglect that this area continues to endure in LMICs more generally. However, this may also simply reflect relatively limited reporting of newborn care interventions in the literature to date, rather than actual intervention priorities in the field. While it is encouraging that most reported neonatal interventions were able to be delivered in hospitals and clinics, there may be missed opportunities to use outreach and community-based sites such as health posts 
or homes, especially when it comes to postnatal care and follow-up for diseases such as HIV. Lower cadre health workers such as CHWs, who seem to be underused when it comes to newborn health, could also be used to deliver these interventions.

There was limited literature on the implementation of the Minimal Initial Service Package (MISP), which is considered key, universal guidance for sexual and reproductive health at the onset of an emergency, including for reducing maternal and neonatal mortality. While a few articles did mention following the MISP guidelines, these did not provide further details on which components. Few publications reported quantitative data, and of those that did, most reported on intervention coverage, mainly ANC coverage. However, even within this one area, there is much variability between publications with respect to how coverage is defined and reported, including with respect to whether such care was provided by skilled health personnel. There is also very limited evidence reported about the effectiveness of these interventions.

Overall, despite the inclusion in this review of many publications reporting on the delivery of $\mathrm{MNH}$ interventions, there remains limited information in the literature on how interventions are delivered, and limited consistency with respect to which aspects of delivery are reported and in how much detail. Stronger scientific reporting of intervention delivery in both the indexed and grey literature, including more detailed information on how interventions were implemented, where and by whom, could ultimately inform and improve future programmatic decision-making in the field.

\section{Study strengths and weaknesses}

While we sought to retrieve a comprehensive selection of the grey literature reporting on $\mathrm{MNH}$ intervention delivery in conflict settings, the very large volume of potentially relevant reports meant that we had to restrict our search, and we may not have captured the full range of relevant interventions and their delivery characteristics. Moreover, at least some gaps in the existing literature likely reflect reporting gaps rather than actual programmatic gaps, given the many constraints on data collection in conflict settings and on humanitarian health responders' time and research capacities. Nonetheless, this is the first review, to our knowledge, to systematically capture and synthesise reported information in both the indexed and grey literature on how $\mathrm{MNH}$ interventions targeting conflict-affected populations have been and are being delivered in the field.

\section{CONCLUSION}

While the challenges of research in humanitarian crises make it difficult to determine how well the existing literature on $\mathrm{MNH}$ intervention delivery in conflict settings reflects what is actually happening in the field, our results indicate a number of potential implications for research, programming and policy. There is a clear need for more and better reporting on how, where and by whom essential interventions are delivered in conflict settings, and more and better evaluation of the effectiveness of the delivery platforms used. In particular, robust evaluation of the wider use of lower level health workers, including those recruited from affected communities, to deliver a range of $\mathrm{MNH}$ interventions outside of camp settings would be especially useful. Further, despite the continued high burden of neonatal mortality in crisis settings, the delivery of newborn health interventions in conflict settings still does not appear to be sufficiently prioritised. This needs to change, urgently.

Twitter Fahad J Siddiqui @fjsepi

Contributors ZAB, MFG and FJS conceptualised the review. FJS created the search strategy and conducted the literature search in electronic databases. DSK conducted the grey literature search. MM, DSK, SM, DA, MK, RPJ, SS and AR screened studies for eligibility and performed data extraction. MM and SM conducted the analysis with support from MFG and FJS. MM drafted the manuscript, and MFG and ZAB critically revised it. All authors approved the final version.

Funding As coordinator of the BRANCH Consortium (Bridging Research \& Action in Conflict Settings for the Health of Women \& Children), the Sick Kids Centre for Global Child Health has received funding for research activities from the International Development Research Centre (IDRC) (108416-002 \& 108640-001), the Norwegian Agency for Development Cooperation (Norad) (QZA-16/0395), the Bill \& Melinda Gates Foundation (OPP1171560), and UNICEF (PCA 20181204). Aga Khan University has received funding for BRANCH activities from the Family Larsson-Rosenquist Foundation.

Map disclaimer The depiction of boundaries on this map does not imply the expression of any opinion whatsoever on the part of BMJ (or any member of its group) concerning the legal status of any country, territory, jurisdiction or area or of its authorities. This map is provided without any warranty of any kind, either express or implied.

Competing interests None declared.

Patient consent for publication Not required.

Provenance and peer review Not commissioned; externally peer reviewed.

Data availability statement All data relevant to the study are included in the article or uploaded as supplemental information.

Supplemental material This content has been supplied by the author(s). It has not been vetted by BMJ Publishing Group Limited (BMJ) and may not have been peer-reviewed. Any opinions or recommendations discussed are solely those of the author(s) and are not endorsed by BMJ. BMJ disclaims all liability and responsibility arising from any reliance placed on the content. Where the content includes any translated material, BMJ does not warrant the accuracy and reliability of the translations (including but not limited to local regulations, clinical guidelines, terminology, drug names and drug dosages), and is not responsible for any error and/or omissions arising from translation and adaptation or otherwise.

Open access This is an open access article distributed in accordance with the Creative Commons Attribution 4.0 Unported (CC BY 4.0) license, which permits others to copy, redistribute, remix, transform and build upon this work for any purpose, provided the original work is properly cited, a link to the licence is given, and indication of whether changes were made. See: https://creativecommons.org/ licenses/by/4.0/.

\section{ORCID iDs}

Reena P Jain http://orcid.org/0000-0001-7004-5093

Shailja Shah http://orcid.org/0000-0003-2329-5027

\section{REFERENCES}

1 World Health Organization. Trends in maternal mortality: 2000 to 2017: estimates by who, UNICEF, UNFPA, world bank group and the United nations population division. Geneva: WHO, 2019.

2 World Health organization. Newborns: reducing mortality, 2019. Available: https://www.who.int/en/news-room/fact-sheets/detail/ newborns-reducing-mortality 
3 Oza S, Cousens SN, Lawn JE. Estimation of daily risk of neonatal death, including the day of birth, in 186 countries in 2013: a vital-registration and modelling-based study. Lancet Glob Health 2014:2:e635-44.

4 Lassi ZS, Salam RA, Das JK, et al. Essential interventions for maternal, newborn and child health: background and methodology. Reprod Health 2014;11 Suppl 1:S1.

5 Wagner Z, Heft-Neal S, Wise PH, et al. Women and children living in areas of armed conflict in Africa: a geospatial analysis of mortality and orphanhood. Lancet Glob Health 2019;7:e1622-31.

6 Wagner Z, Heft-Neal S, Bhutta ZA, et al. Armed conflict and child mortality in Africa: a geospatial analysis. Lancet 2018;392:857-65.

7 United Nations Population Fund (UNFPA). The state of the world population 2015: shelter from the storm. A transformative agenda for women and girls in a crisis-prone world. New York: UNFPA, 2015: 136.

8 WHO, UNICEF. Every newborn: an action plan to end preventable deaths. Geneva: World Health Organization, 2014.

9 IAWG. Inter-Agency field manual on reproductive health in humanitarian settings. New York: Inter-Agency Working Group on Reproductive Health in Crisis, 2018.

10 UNICEF. Children St. newborn health in humanitarian settings: field guide, 2018.

11 Blanchet K, Sistenich V, Ramesh A. An evidence review of research on health interventions in humanitarian crisis. London, UK: London School of Hygiene \& Tropical Medicine, Harvard School of Public Health, Overseas Development Institute, 2015.

12 Blanchet K, Ramesh A, Frison S, et al. Evidence on public health interventions in humanitarian crises. Lancet 2017;390:2287-96.

13 Singh NS, Aryasinghe S, Smith J, et al. A long way to go: a systematic review to assess the utilisation of sexual and reproductive health services during humanitarian crises. BMJ Glob Health 2018;3:e000682.

14 Singh NS, Smith J, Aryasinghe S, et al. Evaluating the effectiveness of sexual and reproductive health services during humanitarian crises: a systematic review. PLoS One 2018;13:e0199300.

15 Warren E, Post N, Hossain M, et al. Systematic review of the evidence on the effectiveness of sexual and reproductive health interventions in humanitarian crises. BMJ Open 2015;5:e008226.

16 World Bank. World bank country and lending groups: the world bank group, 2019. Available: https://datahelpdesk.worldbank.org/ knowledgebase/articles/906519-world-bank-country-and-lendinggroups

17 The EndNote Team. Endnote. Philadelphia, PA: Clarivate Analytics, 2013.

18 Covidence systematic review software Melbourne, Australia: veritas health innovation. Available: www.covidence.org

19 Harris PA, Taylor R, Thielke R, et al. Research electronic data capture (REDCap) - A metadata-driven methodology and workflow process for providing translational research informatics support. $J$ Biomed Inform 2009;42:377-81.

20 StataCorp. Stata statistical software. College Station, TX: StataCorp LP, 2015.

21 Abdelrahim NA, Ahmed HI, Fadl-Elmula IM, et al. Sexually transmitted infections other than HIV/AIDS among women of low socio-economic class attending antenatal clinics in Khartoum, Sudan. Int J STD AIDS 2017;28:781-7.

22 Abdulsalam AA, Bashour HN, Monem FS. Pregnancy outcomes among Palestinian refugee women with sickle cell trait in Damascus, Syria. Saudi Med J 2003;24:986-90.

23 Abu-Rustum R, Ziade MF, Abu-Rustum S, et al. 2076943 the role of ultrasound in the Lebanese outreach setting. Ultrasound Med Biol 2015;41:S40.

24 Aburas R, Mackey T, Najeeb A, et al. Foundation of a maternity and children's healthcare center for displaced syrians. Ann Glob Health 2017;83:12.

25 Adam IF. The influence of maternal health education on the place of delivery in conflict settings of Darfur, Sudan. Confl Health 2015;9:31.

26 Adam IF, Nakamura K, Kizuki M, et al. Relationship between implementing interpersonal communication and mass education campaigns in emergency settings and use of reproductive healthcare services: evidence from Darfur, Sudan. BMJ Open 2015;5:e008285.

27 Augusto GF. Use of services for prevention of mother-to-child transmission in Angola: a retrospective analysis. J Public Health 2016;38:371-7.

28 Banks T, Kang J, Watts I, et al. High hepatitis B seroprevalence and risk factors for infection in pregnant women on the ThailandMyanmar border. J Infect Dev Ctries 2016;10:384-8.
29 Bannink-Mbazzi F, Lowicki-Zucca M, Ojom L, et al. High PMTCT program uptake and coverage of mothers, their partners, and babies in northern Uganda: achievements and lessons learned over 10 years of implementation (2002-2011). J Acquir Immune Defic Syndr 2013;62:e138-45.

30 Bell SA, Lori J, Redman R, et al. Understanding the effects of mental health on reproductive health service use: a mixed methods approach. Health Care Women Int 2016;37:75-96.

31 Benage M, Greenough PG, Vinck P, et al. An assessment of antenatal care among Syrian refugees in Lebanon. Confl Health 2015;9:8.

32 Bile KM, Hafeez A, Kazi GN, et al. Protecting the right to health of internally displaced mothers and children: the imperative of inter-cluster coordination for translating best practices into effective participatory action. East Mediterr Health J 2011;17:981-9.

33 Bouchghoul H, Hornez E, Duval-Arnould X, et al. Humanitarian obstetric care for refugees of the Syrian war. The first 6 months of experience of Gynécologie Sans Frontières in Zaatari Refugee Camp (Jordan). Acta Obstet Gynecol Scand 2015;94:755-9.

34 Brooks HM, Jean Paul MK, Claude KM, et al. Use and disuse of malaria bed nets in an internally displaced persons cAMP in the Democratic Republic of the Congo: a mixed-methods study. PLoS One 2017;12:e0185290.

35 Carrara VI, Hogan C, De Pree C, et al. Improved pregnancy outcome in refugees and migrants despite low literacy on the ThaiBurmese border: results of three cross-sectional surveys. BMC Pregnancy Childbirth 2011;11:45.

36 Carrara VI, Sirilak S, Thonglairuam J, et al. Deployment of early diagnosis and mefloquine-artesunate treatment of falciparum malaria in Thailand: the Tak malaria initiative. PLoS Med 2006;3:e183-64.

37 Carrara VI, Stuetz W, Lee SJ, et al. Longer exposure to a new refugee food ration is associated with reduced prevalence of small for gestational age: results from 2 cross-sectional surveys on the Thailand-Myanmar border. Am J Clin Nutr 2017;105:ajcn148262-90.

38 Cetorelli V. The impact of the Iraq war on neonatal polio immunisation coverage: a quasi-experimental study. $J$ Epidemiol Community Health 2015;69:226-31.

39 Consulting) AiBCA. Ex-Post evaluation of UNICEF humanitarian action for children 2014-2015 in the state of Palestine, 2016.

40 Cossa HA, Gloyd S, Vaz RG, et al. Syphilis and HIV infection among displaced pregnant women in rural Mozambique. Int J STD AIDS 1994;5:117-23.

41 Culbert H, Tu D, O'Brien DP, et al. Hiv treatment in a conflict setting: outcomes and experiences from Bukavu, Democratic Republic of the Congo. PLoS Med 2007:4:e129.

42 Darjani P, Berbari Shaker L. Infant and young child feeding support in Lebanon: strengthening the National system. Field Exchange 2015;48.

43 Deboutte D, O'Dempsey T, Mann G, et al. Cost-Effectiveness of caesarean sections in a post-conflict environment: a case study of Bunia, Democratic Republic of the Congo. Disasters 2013;37 Suppl 1:S105-20.

44 Devine A, Harvey R, Min AM, et al. Strategies for the prevention of perinatal hepatitis $B$ transmission in a marginalized population on the Thailand-Myanmar border: a cost-effectiveness analysis. BMC Infect Dis 2017;17:552.

45 Dolan G, ter Kuile FO, Jacoutot V, et al. Bed nets for the prevention of malaria and anaemia in pregnancy. Trans $R$ Soc Trop Med Hyg 1993;87:620-6.

46 Duckett J. Guidelines for dietary supplementation of pregnant women in a Rwandan refugee cAMP. J R Army Med Corps 1996;142:13-14

47 Erenel H, Aydogan Mathyk B, Sal V, et al. Clinical characteristics and pregnancy outcomes of Syrian refugees: a case-control study in a tertiary care hospital in Istanbul, Turkey. Arch Gynecol Obstet 2017;295:45-50.

48 Fabiani M, Nattabi B, Opio AA, et al. A high prevalence of HIV-1 infection among pregnant women living in a rural district of North Uganda severely affected by civil strife. Trans $R$ Soc Trop Med Hyg 2006;100:586-93

49 Fujiya R, Jimba M, Giacaman R, et al. The influence of economic factors on the location of birth among Palestinian women in Bethlehem during the second Palestinian uprising. Trop Doct 2007;37:13-17.

50 Furuta M, Mori R. Factors Affecting Women's Health-Related Behaviors and Safe Motherhood: A Qualitative Study From a Refugee Camp in Eastern Sudan. Health Care Women Int 2008:29:884-905. 
51 Garnett G. I123 using South-South collaboration to strengthen midwifery skills and competencies in South Sudan. International Journal of Gynecology \& Obstetrics 2012;119:S190-1.

52 Ghebreyesus TA, Alemayehu T, Bosman A, et al. Community participation in malaria control in Tigray region Ethiopia. Acta Trop 1996;61:145-56.

53 Hafeez A, Riaz R, Ullah Shah S, et al. Integrating health care for mothers and children in refugee camps and at district leve. BMJ 2004;328:834-6.

54 Hammoury N, Khawaja M, Mahfoud Z, et al. Domestic violence against women during pregnancy: the case of Palestinian refugees attending an antenatal clinic in Lebanon. J Womens Health 2009;18:337-45.

55 Hartman F, Rumunu J, Guma V. Increasing access to malaria prevention in South Sudan by integrating net distribution and intermittent preventive treatment with antenatal care and immunizations. American Journal of Tropical Medicine and Hygiene 2012;87:410-1.

56 Holt BY, Effler P, Brady W, et al. Planning STI/HIV prevention among refugees and mobile populations: situation assessment of Sudanese refugees. Disasters 2003;27:1-15.

57 Homan FF, Hammond CS, Thompson EF, et al. Post-conflict transition and sustainability in Kosovo: establishing primary healthcare-based antenatal care. Prehosp Disaster Med 2010;25:28-33.

58 Hoogenboom G, Thwin MM, Velink K, et al. Quality of intrapartum care by skilled birth attendants in a refugee clinic on the ThaiMyanmar border: a survey using who safe motherhood needs assessment. BMC Pregnancy Childbirth 2015;15:17.

59 Huster KMJ, Patterson N, Schilperoord M, et al. Cesarean sections among Syrian refugees in Lebanon from December 2012/january 2013 to June 2013: probable causes and recommendations. Yale $J$ Biol Med 2014:87:269-88.

60 Hynes M, Meehan K, Meyers J, et al. Using a quality improvement approach to improve maternal and neonatal care in North Kivu, Democratic Republic of Congo. Reprod Health Matters 2017;25:140-50.

61 Ing H, Fellmeth G, White J, et al. Validation of the Edinburgh postnatal depression scale (EPDS) on the Thai-Myanmar border. Trop Doct 2017;47:339-47.

62 Jambai A, MacCormack C, health M. Maternal health, war, and religious tradition: authoritative knowledge in Pujehun district, Sierra Leone. Med Anthropol Q 1996;10:270-86.

63 Kabakian-Khasholian T, Mourtada R, Bashour H, et al. Perspectives of displaced Syrian women and service providers on fertility behaviour and available services in West Bekaa, Lebanon. Reprod Health Matters 2017;25:75-86.

64 Kabakian-Khasholian T, Shayboub R, El-Kak F. Seeking maternal care at times of conflict: the case of Lebanon. Health Care Women Int 2013;34:352-62.

65 Kassim IAR, Ruth LJ, Creeke PI, et al. Excessive iodine intake during pregnancy in Somali refugees. Matern Child Nutr 2012;8:49-56.

66 Khader A, Madi H, Riccardo F, et al. Anaemia among pregnant Palestinian women in the occupied Palestinian Territory. Public Health Nutr 2009;12:2416-20.

67 Khan MN, Dherani M, Chiumento A, et al. Evaluating feasibility and acceptability of a local psycho-educational intervention for pregnant women with common mental problems affected by armed conflict in Swat, Pakistan: a parallel randomized controlled feasibility trial. Int J Soc Psychiatry 2017;63:724-35.

68 Khawaja M, Hammoury N. Coerced sexual intercourse within marriage: a Clinic-Based study of pregnant Palestinian refugees in Lebanon. J Midwifery Womens Health 2008;53:150-4.

69 Kibiribiri ET, Moodley D, Groves AK, et al. Exploring disparities in prenatal care between refugees and local South African women. Int J Gynaecol Obstet 2016;132:151-5.

70 Kitabayashi $\mathrm{H}$, Chiang C, Al-Shoaibi AAA, et al. Association between maternal and child health Handbook and quality of antenatal care services in Palestine. Matern Child Health J 2017;21:2161-8

71 Krause S, Williams H, Onyango MA, et al. Reproductive health services for Syrian refugees in Zaatri cAMP and Irbid City, Hashemite Kingdom of Jordan: an evaluation of the minimum initial services package. Confl Health 2015;9:S4.

72 Krause SK, Meyers JL, Friedlander E. Improving the availability of emergency obstetric care in conflict-affected settings. Glob Public Health 2006;1:205-28.

73 Kruk ME, Rockers PC, Williams EH, et al. Availability of essential health services in post-conflict Liberia. Bull World Health Organ 2010;88:527-34.
74 Lee RB. Delivering maternal health care services in an internal conflict setting in Maguindanao, Philippines. Reprod Health Matters 2008;16:65-74.

75 Luxemburger C, White NJ, ter Kuile F, et al. Beri-Beri: the major cause of infant mortality in Karen refugees. Trans $R$ Soc Trop Med Hyg 2003;97:251-5.

76 Madanat $\mathrm{H}$, Farrell H, Merrill R, et al. Breastfeeding education, support, and barriers among Iraqi refugee women in Jordan. Int Electr J Health Educ 2007;10:138-49.

77 Mayaud P. The challenge of sexually transmitted infections control for HIV prevention in refugee settings: Rwandan refugees in Tanzania. Trans R Soc Trop Med Hyg 2001;95:121-4.

78 Mayhew M, Hansen PM, Peters DH, et al. Determinants of skilled birth attendant utilization in Afghanistan: a cross-sectional study. Am J Public Health 2008:98:1849-56.

79 McGinn T, Allen K. Improving refugees' reproductive health through literacy in guinea. Glob Public Health 2006;1:229-48.

80 McGready R, Boel M, Rijken MJ, et al. Effect of early detection and treatment on malaria related maternal mortality on the northwestern border of Thailand 1986-2010. PLoS One 2012;7:e40244.

81 McGready R, Kang J, Watts I, et al. Low and stable rates of antenatal syphilis and HIV in migrant and refugee women on the Thai-Myanmar border: a descriptive study. F1000Research 2014;3:123

82 McGready R, Simpson JA, Cho T, et al. Postpartum thiamine deficiency in a Karen displaced population. Am J Clin Nutr 2001;74:808-13.

83 McGready R, Day NP, Jesadapanpong W, et al. Diagnostic and treatment difficulties of pyelonephritis in pregnancy in resourcelimited settings. Am J Trop Med Hyg 2010;83:1322-9.

84 McGregor K, Myat Min A, Karunkonkowit N, et al. Obstetric ultrasound AIDS prompt referral of gestational trophoblastic disease in marginalized populations on the Thailand-Myanmar border. Glob Health Action 2017;10:1296727.

85 McPherson RA, Khadka N, Moore JM. Are birth-preparedness programmes effective? results from a field trial in Siraha district, Nepal. J Health Popul Nutr 2006;24:479-88.

86 Mercer SW, Sevar K, Sadutshan TD. Using clinical audit to improve the quality of obstetric care at the Tibetan Delek hospital in North India: a longitudinal study. Reprod Health 2006;3:4.

87 Miller LC, Jami-Imam F, Timouri M, et al. Trained traditional birth attendants as educators of refugee mothers. World Health Forum 1995;16:151-6.

88 Mohammadi S, Saleh Gargari S, Fallahian M, et al. Afghan migrants face more suboptimal care than natives: a maternal near-miss audit study at university hospitals in Tehran, Iran. BMC Pregnancy Childbirth 2017;17:64.

89 Morrison V. Contraceptive need among Cambodian refugees in Khao Phlu cAMP. Int Fam Plan Perspect 2000;26:188-92.

90 Msuya W, Mayaud P, Mkanje R, et al. Taking early action in emergencies to reduce the spread of STDs and HIV. Afr Health 1996; $18: 24$

91 Mucunguzi S, Wamani H, Lochoro P, et al. Effects of improved access to transportation on emergency obstetric care outcomes in Uganda. Afr J Reprod Health 2014;18:87-94.

92 Muhammad HU, Giwa FJ, Olayinka AT, et al. Malaria prevention practices and delivery outcome: a cross sectional study of pregnant women attending a tertiary hospital in northeastern Nigeria. Malar J 2016;15:326.

93 Mullany LC, Lee Cl, Yone L, et al. Access to essential maternal health interventions and human rights violations among vulnerable communities in eastern Burma. PLoS Med 2008;5:e242-98.

94 Mullany LC, Lee Cl, Paw P, et al. The mom project: delivering maternal health services among internally displaced populations in eastern Burma. Reprod Health Matters 2008;16:44-56.

95 Mullany LC, Lee TJ, Yone L, et al. Impact of community-based maternal health workers on coverage of essential maternal health interventions among internally displaced communities in eastern Burma: the mom project. PLoS Med 2010;7:e1000317.

96 Muller MM, Salmon M, Salmon C, et al. Utilisation of focused assessment with sonography for trauma (fast) in a referral hospita in an acute conflict zone. African Journal of Emergency Medicine 2015;5:7-11.

97 Musmar SG, Qanadeelu S. Breastfeeding patterns among Palestinian infants in the first 6 months in Nablus refugee camps: a cross-sectional study. J Hum Lact 2012;28:196-202.

98 Nosten F, McGready R, Simpson JA, et al. Effects of Plasmodium vivax malaria in pregnancy. Lancet 1999;354:546-9.

99 Nosten F, ter Kuile F, Maelankirri L, et al. Malaria during pregnancy in an area of unstable endemicity. Trans $R$ Soc Trop Med Hyg $1991 ; 85: 424-9$. 
$100 \mathrm{Obol} \mathrm{JH}$, Ononge S, Orach CG. Utilisation of insecticide treated nets among pregnant women in Gulu: a post conflict district in northern Uganda. Afr Health Sci 2013;13:962-9.

101 Odero W, Otieno-Nyunya B. Major obstetric interventions among encamped refugees and the local population in Turkana district, Kenya. East Afr Med J 2001;78:666-72.

102 Orach CG, De Brouwere V. Postemergency health services for refugee and host populations in Uganda, 1999-2002. Lancet 2004;364:611-2.

103 Parr M, Dabu CP, Wai NS, et al. Clinical audit to enhance safe practice of skilled birth attendants for the fetus with nuchal cord: evidence from a refugee and migrant cohort. BMC Pregnancy Childbirth 2014;14:76

104 Pearson L, Shoo R. Availability and use of emergency obstetric services: Kenya, Rwanda, southern Sudan, and Uganda. Int J Gynaecol Obstet 2005;88:208-15.

105 Plewes K, Lee T, Kajeechewa L, et al. Low seroprevalence of HIV and syphilis in pregnant women in refugee camps on the ThaiBurma border. Int J STD AIDS 2008;19:833-7.

106 Purdin S, Khan T, Saucier R. Reducing maternal mortality among Afghan refugees in Pakistan. Int J Gynaecol Obstet 2009;105:82-5.

107 Rijken MJ, Lee SJ, Boel ME, et al. Obstetric ultrasound scanning by local health workers in a refugee cAMP on the Thai-Burmese border. Ultrasound Obstet Gynecol 2009;34:395-403.

108 Ruckstuhl L, Lengeler C, Moyen JM, et al. Malaria case management by community health workers in the central African Republic from 2009-2014: overcoming challenges of access and instability due to conflict. Malar J 2017;16:388.

109 Rull M, Masson S, Peyraud N, et al. The new who decision-making framework on vaccine use in acute humanitarian emergencies: MSF experience in Minkaman, South Sudan. Confl Health 2018;12:11.

110 Rutta E, Gongo R, Mwansasu A, et al. Prevention of mother-tochild transmission of HIV in a refugee cAMP setting in Tanzania. Glob Public Health 2008;3:62-76.

111 Sami S, Kerber K, Kenyi S, et al. State of newborn care in South Sudan's displacement camps: a descriptive study of facility-based deliveries. Reprod Health 2017;14:161.

112 Sami S, Kerber K, Tomczyk B, et al. "You have to take action": changing knowledge and attitudes towards newborn care practices during crisis in South Sudan. Reprod Health Matters 2017;25:124-39.

113 Schaider J, Ngonyani S, Tomlin S, et al. International maternal mortality reduction: outcome of traditional birth attendant education and intervention in Angola. J Med Syst 1999;23:99-105.

114 Shaikh MA. Nurses' use of global information systems for provision of outreach reproductive health services to internally displaced persons. Prehosp Disaster Med 2008;23:s35-8.

115 Shrimpton R, Thorne-Lyman A, Tripp K, et al. Trends in low birthweight among the Bhutanese refugee population in Nepal. Food Nutr Bull 2009;30:S197-206.

116 Simetka O, Reilley B, Joseph M, et al. Obstetrics during civil war: six months on a maternity ward in Mallavi, Northern Sri Lanka. Med Confl Surviv 2002;18:258-70.

117 Sivaganesh S, Senarath U. Antenatal care utilization in a conflictaffected district of northern Sri Lanka. Public Health Nurs 2009;26:512-22.

118 Somigliana E, Sabino A, Schrettenbrunner C, et al. A comprehensive and integrated project to improve reproductive health at Oyam district, Northern Uganda: insights from maternal death review at the district hospital. Arch Gynecol Obstet 2011;283:645-9.

119 Stein W, Katundo I, Byengonzi B. Caesarean rate and uterine rupture: a 15-year hospital-based observational retrospective study in rural Tanzania. Z Geburtshilfe Neonatol 2008;212:222-5.

120 Tatah L, Delbiso TD, Rodriguez-Llanes JM, et al. Impact of refugees on local health systems: a difference-in-differences analysis in Cameroon. PLoS One 2016;11:e0168820.

121 Tomé T, Silva F, Rodrigues K. Saving lives after civil war. World Health 1998;51:24-5.

122 Tran NT, Harker K, Yameogo WME, et al. Clinical outreach refresher trainings in crisis settings (S-CORT): clinical management of sexual violence survivors and manual vacuum aspiration in Burkina Faso, Nepal, and South Sudan. Reprod Health Matters 2017;25:103-13

123 Turner C, Carrara V, Aye Mya Thein N, et al. Neonatal intensive care in a Karen refugee cAMP: a 4 year descriptive study. PLoS One 2013;8:e72721.

124 Turner C, Turner P, Hoogenboom G, et al. A three year descriptive study of early onset neonatal sepsis in a refugee population on the Thailand Myanmar border. BMC Infect Dis 2013;13:601.

125 United Nations Children's Fund (UNICEF). The UNICEF response to the crisis in the central African Republic: final report, 2016.

126 United Nations High Commissioner for Refugees (UNHCR). Cashbased interventions for health programmes in refugee settings: a review, 2015

127 United Nations Population Fund (UNFPA). Adolescent Girls in Disaster \& Conflict: Interventions for Improving Access to Sexual and Reproductive Health Services 2016, 2016.

128 Van Damme W, De Brouwere V, Boelaert M, et al. Effects of a refugee-assistance programme on host population in guinea as measured by obstetric interventions. Lancet 1998;351:1609-13.

129 Viswanathan K, Hansen PM, Rahman MH, et al. Can community health workers increase coverage of reproductive health services? $\checkmark$ Epidemiol Community Health 2012;66:894-900.

130 Von Roenne A, Von Roenne F, Kollie S, et al. Reproductive health services for refugees by refugees: an example from guinea. Disasters 2010;34:16-29.

131 Wayte K, Zwi AB, Belton S, et al. Conflict and development: challenges in responding to sexual and reproductive health needs in Timor-Leste. Reprod Health Matters 2008;16:83-92.

132 West L, Isotta-Day H, Ba-Break M, et al. Factors in use of family planning services by Syrian women in a refugee cAMP in Jordan. $J$ Fam Plann Reprod Health Care 2017;43:96-102.

133 White AL, Carrara VI, Paw MK, et al. High initiation and long duration of breastfeeding despite absence of early skin-to-skin contact in Karen refugees on the Thai-Myanmar border: a mixed methods study. Int Breastfeed J 2012;7:19.

134 White AL, Min TH, Gross MM, et al. Accelerated training of skilled birth attendants in a Marginalized population on the Thai-Myanmar border: a multiple methods program evaluation. PLoS One 2016;11:e0164363.

135 Desie S. Somalia nutrition cluster: integrated famine prevention package. field exchange, 2017: 56.

136 Inter-Agency Working Group on Reproductive Health in Crises (IAWG). Surviving day one: caring for mothers and newborns in humanitarian emergencies on the day of childbirth, 2019. 